\title{
O CUIDADO CENTRADO NA PESSOA EM PERSPECTIVA DIALÓGICA: UMA ANÁLISE DAS FALAS ENTRE FONOAUDIÓLOGA E PACIENTES COM QUEIXA DE ZUMBIDO
}

\section{PERSON-CENTERED CARE IN DIALOGICAL PERSPECTIVE: AN ANALYSIS OF SPEECHES BETWEEN PHONOAUDIOLOGIST AND PATIENTS WITH TINNITUS COMPLAINT}

\author{
Amanda Câmara Miranda* \\ GEPAEZ -UFPB \\ Wilder Kleber Fernandes de Santana* \\ PROLING-UFPB
}

\section{Marine Raquel Diniz da Rosa ${ }^{* * *}$ \\ PPGNEC-UFPB}

\begin{abstract}
Resumo: Este trabalho objetivou realizar uma análise do discurso do profissional fonoaudiólogo com base na teoria dialógica durante o atendimento de pacientes com zumbido utilizando o Cuidado Centrado na Pessoa. Temos em vista a construção da Interação discursiva (VOLÓCHINOV, 2017) a partir do momento que a profissional se utiliza do Cuidado Centrado na Pessoa. Nesse sentido, nossa pretensão foi averiguar como os sentidos se concretizam no diálogo entre a fonoaudióloga e seus pacientes. Os dizeres aqui construídos têm subsídio teórico nos pressupostos de Bakhtin (2006a, 2006b, 2010), Volóchinov (2017) e Medviédev (2016), ao tratarem da problemática do discurso. Em perspectiva dialógico-discursiva, no âmbito das discussões em Ciências Humanas, divide-se este trabalho em três seções. Buscamos, na primeira seção, apresentar considerações basilares sobre o zumbido e como este é tratado por meio do Cuidado Centrado na Pessoa. Na segunda seção, realizamos uma discussão sobre a importância do uso do Cuidado Centrado na Pessoa no atendimento de pacientes com zumbido; enquanto a terceira seção compreende a análise, em que averiguamos, por meio de abordagem dialógica, o discurso da profissional fonoaudióloga sobre zumbido.
\end{abstract}

Palavras-chave: Zumbido. Cuidado Centrado na Pessoa. Dialogismo.

\footnotetext{
${ }^{*}$ Mestra em Neurociência Cognitiva e Comportamento pela Universidade Federal da Paraíba (UFPB). Pós-graduada em Audiologia pelo Instituto de Desenvolvimento Educacional. Participante do Grupo de Estudo e Pesquisa em Audição, Equilíbrio e Zumbido (GEPAEZ). ORCID: https://orcid.org/0000-0002-3136-6633. E-mail: <mirandaamandac@outlook.com>.

** Doutorando e Mestre em Linguística pela Universidade Federal da Paraíba (UFPB). Mestre em Teologia pela Faculdade Teológica Nacional. Membro-pesquisador do Grupo de Pesquisa em Linguagem, Enunciação e Interação (GPLEI-CNPQ) - UFPB. ORCID: https://orcid.org/0000-0001-7569-499X. E-mail: <wildersantana92@gmail.com>.

${ }^{* * *}$ Professora Associada I do curso de Fonoaudiologia da Universidade Federal da Paraíba (UFPB). Docente e pesquisadora dos Programas de Pós-Graduação em Neurociência Cognitiva e Comportamento (PPgNeC) e de Fonoaudiologia (PPGFON). ORCID: https://orcid.org/0000-0003-0920-2234. E-mail: <mrdrosa@yahoo.com.br>.
} 
Abstract: This work aimed to carry out an analysis of the speech of the therapist based on the dialogic theory during the care of patients with tinnitus using Person-Centered Care. We have in mind the construction of discursive interaction (VOLÓCHINOV, 2017) from the moment the professional uses Person-Centered Care. In this sense, our intention was to find out how the senses are realized in the dialogue between the speech therapist and her patients. The statements constructed here have theoretical support in the assumptions of Bakhtin (2006a, 2006b, 2010), Volóchinov (2017) and Medviédev (2016), when dealing with the problem of discourse. In a dialogical-discursive perspective, within the scope of discussions in Human Sciences, this paper is divided into three sections. In the first section 1, we seek to present basic considerations about tinnitus and how it is treated through Person-Centered Care. In the second section, we discuss the importance of using person-centered care in the care of patients with tinnitus, while the third section comprises the analysis, in which we verified, through a dialogical approach, the speech of the therapist about tinnitus.

Keywords: Tinnitus. Person-Centered Care. Dialogism.

\section{INTRODUÇÃO}

Nosso trabalho insere-se no hall de debates que já vem sendo desenvolvido por profissionais das áreas de linguagem e de fonoaudiologia sobre o Zumbido, uma vez que diversas discussões têm sido empreendidas em terreno vernáculo e internacional (ESTEVES et al., 2012; ONISHI et al., 2018; ROSA, 2012 et al.), ao investigar como esse sintoma se relaciona a outras áreas do saber, e para diferentes finalidades. Essas modalidades de percepção do profissional exigem novos modos de organização do trabalho, produzindo dinâmicas diferenciadas.

O zumbido pode ser um sintoma devastador, já que uma proporção significativa de portadores de zumbido desenvolve distúrbios do sono, depressão e outras comorbidades psiquiátricas, levando uma pequena fração a cometer suicídio (HENRY et al., 2005). Diante da interferência negativa na vida do paciente, é necessário que os profissionais tenham a sensibilidade de atender às necessidades do indivíduo de forma ampla, e não se ater apenas à doença, mas a tudo que está ao redor dela (STARFIELD, 2011).

Em relação ao problema de pesquisa, foi averiguado que, a partir da conduta do profissional na relação com o paciente e na condução do problema que ele traz, no caso, o zumbido, boa parte dos pacientes começam a se sentir mais acolhidos e consequentemente se sentem mais à vontade para falar sobre seu problema, assim se sentindo mais seguros e esperançosos com a ajuda que é oferecida pelo profissional desde o contato inicial. Assim, refletimos: Como a postura discursiva do profissional contribui para o alívio dos sintomas do zumbido? Esse trabalho justifica-se tendo em vista pesquisas que mostram que o zumbido e os fatores emocionais apresentam relação de causa e efeito, podendo existir aumento da percepção do zumbido quando algum fator emocional estiver associado. Diante da dificuldade que os profissionais têm encontrado no manejo com o paciente com queixa de zumbido, é comum que estes cheguem aos serviços com uma carga emocional negativa muito grande, proporcionando, consequentemente, o aumento da preocupação e do incomodo do zumbido.

Assim sendo, o presente trabalho objetivou realizar uma análise do discurso do profissional fonoaudiólogo com base na teoria dialógica durante o atendimento de pacientes com zumbido, 
utilizando o Cuidado Centrado na Pessoa (CCP). Temos em vista a construção da Interação discursiva (VOLÓCHINOV, 2017) ${ }^{1}$ a partir do momento que a profissional se utiliza do CCP. A interação discursiva convoca um repertório de diálogo entre consciências e remissão a outras vozes por parte dos interlocutores, para corroborar seus discursos. Então, sua concretude dá-se no instante em que percebemos o diálogo concreto entre a fonoaudióloga e seu(s) outro(s) ${ }^{2}$, não apenas em atos de concordância, mas criando elo(s) nessa incessante rede de dizeres e de posicionamentos semântico-axiológicos (SANTANA, 2019a). Dentre oito pacientes que constituíam nossa população, selecionamos como amostra quatro, cujo critério de seleção se deu pela centralização discursiva no zumbido. Para manter a integridade e o compromisso ético, atribuímos nomes fictícios aos pacientes, quais sejam: José, Juliana, Cirineu e Joana.

Compreendemos que a Interação discursiva presente em algumas formas de discurso não apenas orienta os profissionais envolvidos na comunicação, mas ajuda os analistas de discurso na interpretação do conteúdo citado, além de contribuir para a reavaliação das sessões clínicas. Todos esses aspectos compõem o horizonte ideológico, que, segundo Todorov (2006), em prefácio à Estética da Criação Verbal, consiste em um conjunto de ideias nas quais estão presentes vozes constituintes ${ }^{3}$.

Em termos estruturais, após a Introdução, buscamos, na primeira seção, apresentar Considerações basilares sobre o zumbido e como este é tratado por meio do Cuidado Centrado na Pessoa. Na segunda seção, realizamos uma discussão sobre a importância do uso do Cuidado Centrado na Pessoa no atendimento de pacientes com zumbido, enquanto a terceira seção compreende a análise, em que averiguamos, por meio de abordagem dialógica, o discurso da profissional fonoaudióloga sobre zumbido.

\section{BREVES CONSIDERAÇÕES SOBRE O ZUMBIDO E COMO ESTE É TRATADO POR MEIO DO CUIDADO CENTRADO NA PESSOA}

O zumbido, tinnitus, é a sensação auditiva na ausência de uma fonte sonora externa (GUIMARÃES et al., 2014). O termo tinnitus, empregado na língua inglesa, deriva do verbo tinnire em Latim, que significa tocar ou ressoar, demonstrando a sensação e a percepção do som que não está presente no ambiente (BAGULEY et al., 2013).

Estima-se a prevalência em 10 a 15\% da população adulta, e que $22 \%$ da população de São Paulo sofre com o zumbido (OITICICA; BITTAR, 2015). Pode ser causado por várias condições médicas: afecções otológicas, metabólicas, neurológicas, cardiovasculares, farmacológicas, odontológicas, psicológicas, efeitos colaterais de medicamentos e possivelmente da ingestão de drogas, cafeína, nicotina e álcool (GRANJEIRO et al., 2008; NONDAHL et al., 2011). O atendimento aos pacientes com zumbido é um desafio contínuo, por tratar-se

\footnotetext{
${ }^{1} \mathrm{Na}$ óptica de Santana (2019b, p. 216): “A partir do instante em que delimitamos uma palavra que possa permear diversas áreas do saber, e ao mesmo tempo dialogar com diversas épocas e lugares, acumulando-se seus sentidos, estamos diante de uma proposta dialógica. Na perspectiva de Volóchinov ((2017 [1929]), a palavra não é colocada apenas como o signo mais puro, mais indicativo”. Dito de outra forma, é na Interação discursiva que compreendemos a manifestação viva da palavra, e não de forma isolada, como proposto de forma mecânica pelo positivismo.

${ }^{2}$ Quando mencionamos “seus outros”, estamos nos referindo aos pacientes, que estão em processo dialogal.

${ }^{3} \mathrm{Na}$ percepção do crítico francês, esse percurso é acessado por meio de uma arte dialógica, a qual nos conduz a um terceiro estado, situado além do verdadeiro e do falso, do bem e do mal (TODOROV, 2006).
} 
de sintoma relacionado a diferentes patologias subjacentes, muitas vezes acompanhado por diversas comorbidades. Assim sendo, há necessidade de diagnóstico, avaliação e tratamento multidisciplinar desses pacientes (SANCHEZ et al., 1997).

Apesar de essa investigação ser feita de forma completa, muitas vezes o paciente não se sente confortável em expor todas as informações, ou, então, isso é feito de forma muito impessoal. Com isso, os profissionais vêm encontrando muitos obstáculos para lidar com o paciente e a incerteza da melhora do zumbido. Então, atualmente, vem sendo utilizado o atendimento com base no CCP para essa população, visando auxiliar o contato inicial, proporcionando uma melhor comunicação profissional-paciente.

No CCP, o profissional busca enfatizar que, apesar de condições crônicas poderem não ser curadas, suas consequências podem ser minimizadas com o autogerenciamento, isto é, a adoção, a modificação e/ou a manutenção de comportamentos saudáveis (LAWN; SCHOO, 2010). Autogerenciamento refere-se à capacidade de o indivíduo gerenciar os sintomas, tratamento, consequências físicas, psicossociais e mudanças no estilo de vida, que são inerentes a viver com uma condição crônica (BARLOW et al., 2002). Dessa forma, o CCP tem sido sugerido como uma parte fundamental do gerenciamento bem-sucedido de condições crônicas de saúde (MICHIE et al., 2003). Diante disso, o CCP irá trabalhar os aspectos psicossociais do zumbido, promovendo um cuidado de saúde projetado em torno das necessidades, dos desejos e das perspectivas do paciente por meio da empatia, aconselhamento, escuta aberta e de um bom relacionamento profissional de saúde-paciente. Para concretização do trabalho, utilizamo-nos de ferramentas com base no CCP fornecidas pelo IDA Institute 4 para o atendimento de indivíduos com zumbido.

É corriqueiro, no relato dos pacientes, que eles já passaram por vários profissionais e a resposta que têm é que precisam se acostumar com o zumbido, pois o sintoma não terá jeito, deixando-os com a sensação de que "nada pode ser feito", fazendo com que se sintam ainda mais abalados diante do problema. Dessa forma, torna-se necessário que haja uma comunicação profissional de saúde-paciente diferenciada desde o acolhimento desses pacientes, os confortando e os estimulando para o tratamento posterior.

Então, surge a possibilidade de um atendimento que preconiza essas perspectivas, que é o atendimento com base no CCP, porém existe uma escassez de pesquisas que falem sobre o tema e o uso desse tipo de abordagem no atendimento para essa população, tornando-se, assim, necessária a validação das ferramentas em outros idiomas para que profissionais de diversos países possam utilizá-los na sua prática clínica e, a partir daí, possam surgir trabalhos que comprovem a eficácia desse atendimento.

No que se refere ao zumbido, foram desenvolvidas algumas ferramentas para auxiliar nesse processo, porém estas têm sido pouco utilizadas até o momento. Assim, a evidência empírica para essa população é limitada, com apenas um pequeno número de estudos publicados sobre centralização do paciente específicos para audiologia(GRENNESS et al., 2014; LAPLANTELÉVESQUE et al., 2011).

\footnotetext{
${ }^{4} \mathrm{O}$ Ida Institute, uma instituição sem fins lucrativos dinamarquesa, baseia-se nisto e fornece aos audiologistas informação e apoio para ajudar a orientar as pessoas com dificuldades auditivas para uma reabilitação bem-sucedida. Por preconizar que uma abordagem holística para o cuidado aliado a uma comunicação eficaz é fundamental para o sucesso da reabilitação, faz com que este paciente se sinta compreendido desde o momento do contato inicial.
} 
O termômetro para o zumbido, que é uma escala de classificação adaptada da Escala Visual Analógica (EVA), é utilizado para avaliar como os pacientes estão lidando com o zumbido no momento da consulta e também pode ser usada para monitorar o desempenho do paciente ao longo do tempo. A EVA consiste em auxiliar na aferição da intensidade da dor no paciente, consistindo em um instrumento importante para se verificar a evolução do paciente durante o tratamento e mesmo a cada atendimento, de maneira mais fidedigna. Também é útil para constatação de efetivação do tratamento, bem como quais procedimentos têm surtido melhores resultados, assim como se há alguma deficiência no tratamento, de acordo com o grau de melhora ou piora da dor (AZEVEDO et al., 2007).

Nos pacientes com zumbido especificamente, pede-se para o paciente atribuir uma nota de 0 a 10 para o seu zumbido, com o auxílio de uma régua apropriada, a avaliação deve ser feita com relação ao volume e ao incômodo: 0 significa ausência total de incômodo; e 10, o nível de dor máxima suportável pelo paciente. Ela é usada para avaliar como os pacientes estão lidando com o zumbido no momento da consulta e também pode ser usada para monitorar o desempenho do paciente ao longo do tempo, quando houver melhora também pode ser mostrada para o paciente para ajudá-lo a perceber que as suas perspectivas do zumbido podem mudar para melhor ao longo de tempo (FIGUEIREDO; AZEVEDO; OLIVEIRA, 2009).

Quando houver melhora, também pode ser mostrado o termômetro para o paciente para ajudá-lo a perceber que as suas perspectivas do zumbido podem mudar para melhor ao longo do tempo. No momento da utilização do termômetro, o paciente é orientado a serem realizadas perguntas abertas para estruturar a conversa assim como escutar ativamente e dar espaço para que o paciente expresse seus pensamentos e sentimentos (IDA INSTITUTE, 2018).

O guia de comunicação de zumbido ajuda para que o profissional se comunique de maneira eficaz e empática com os pacientes. As perguntas abertas são orientadas para que se crie espaço para o paciente compartilhar como o zumbido vem afetando sua vida, podendo ajudá-los a lidar com emoções difíceis e se sintam menos sozinhos. Elas servem também para que o paciente consiga articular seus pensamentos e fazer também perguntas a respeito do zumbido, assim o profissional pode resolver qualquer equívoco que ele possa ter a respeito do seu sintoma. O guia também preconiza que o profissional expresse empatia enquanto escuta o que é dito pelo paciente, a fim de fazer com que ele perceba que está sendo ouvido ativamente. Essa empatia é demonstrada com frases como "isso parece muito difícil para você"; "entendo que você quer que seu zumbido desapareça - eu também gostaria disso” (IDA INSTITUTE, 2018, n.p., tradução nossa).

No guia de comunicação também é fornecido o gráfico de previsão do zumbido para ajudar o profissional a explicar a diferença entre quão presente (alto) o som do zumbido é e quão intrusivo (angustiante) é. Com ele é possível promover a esperança nos pacientes e a pensar no zumbido de maneira mais construtiva. Assim, ao compartilhar essas informações no início do tratamento, pode gerar um impacto sobre como os pacientes vão lidar com o zumbido em longo prazo (IDA INSTITUTE, 2018).

O kit de primeiros socorros é composto por orientações com a finalidade de acalmar e auxiliar o paciente a dar os primeiros passos, dando algumas dicas para ajudar a lidar com o zumbido até agendar a consulta com um especialista (IDA INSTITUTE, 2018). Existe uma escassez de pesquisas que mostrem a importância dessa forma de conduta para essa população, 
visto que esses pacientes necessitam de atenção e uma escuta direcionada. Tal abordagem poderá fazer diferença no resultado da intervenção proposta posteriormente.

Então, foi realizada a tradução de todo o material do inglês para o português brasileiro por uma equipe composta por três alunos e um professor do curso de tradução e a revisão após a tradução foi realizada por duas professoras e uma aluna fluente em inglês. Inicialmente, entrou-se em contato com o IDA Institute para ser firmada a parceira da tradução. Após, o IDA disponibilizou o material original e foi realizada a tradução dele, que está disponível no portal eletrônico https://idainstitute.com/tools/tinnitus/. Esse material foi elaborado com o intuito de fornecer aos profissionais audiologistas, que atendem a pacientes com zumbido, ferramentas baseadas no CCP, a fim de capacitá-los para a sua utilização na prática clínica.

Seguindo o princípio de que a tradução deve ser realizada por pelo menos dois tradutores independentes nativos do país e cientes do objetivo de estudo para detecção de possíveis interpretações divergentes de termos ou expressões ambíguas, a tradução do inglês para o português brasileiro foi realizada por uma equipe composta por três alunos e dois professores do curso de tradução (bacharelado) da Universidade Federal da Paraíba (UFPB).

Após a tradução, foram realizados os atendimentos usando o material proposto, foram atendidos oito pacientes com zumbido, os quais ainda não tinham sido submetidos a nenhum outro tipo de atendimento. O profissional responsável por fazê-los realizou o curso disponível no site do IDA Institute para o aprimoramento dos atendimentos. No total, foram realizados e filmados oito atendimentos, porém apenas quatro foram selecionados para análise.

\section{A IMPORTÂNCIA DO USO DO CUIDADO CENTRADO NA PESSOA NO ATENDIMENTO DE PACIENTES COM ZUMBIDO}

O zumbido é uma percepção auditiva fantasma, percebida exclusivamente pelo paciente. Essa característica subjetiva dificulta as pesquisas, limitando as condições de investigação de sua fisiopatologia. Muitos profissionais apresentam dificuldades em lidar com o paciente portador de zumbido, e isso se deve a dois fatores principais. Em primeiro lugar, o zumbido é sintoma alusivo e o desconforto causado é subjetivo, tornando difícil a avaliação médica. Em segundo, há insuficiência de descrições sobre o assunto, mesmo nos melhores livros-texto, o que faz o profissional sentir-se despreparado para lidar com o paciente(SANCHEZ et al., 1997).

O avanço tecnológico na área de saúde trouxe importantes progressos no diagnóstico e no tratamento de várias doenças, criando novas possibilidades para o controle de doenças e sintomas crônicos e contribuindo para o aumento da expectativa de vida da população. No entanto, ainda permanecem grandes desafios para a garantia da qualidade dos cuidados em saúde. Problemas de comunicação e de relacionamento entre os profissionais e o paciente ocorrem com frequência, os quais interferem na percepção do paciente sobre a qualidade do cuidado. Dwamena et al. (2012), em seus estudos, constataram que muitos pacientes estão insatisfeitos com a qualidade da interação com o profissional de saúde e acabam levando essa insatisfação para o tratamento.

A relação profissional de saúde-paciente é uma relação interpessoal complexa, que possui forte carga emocional e requer cooperação mútua, para que um objetivo comum seja atingido. Aprimorar os processos envolvidos nessa relação é determinante para a humanização e a 
qualidade dos serviços prestados. As dimensões humana, vivencial, psicológica e cultural da doença precisam ser consideradas nas relações profissional-paciente (GOULART; CHIARI, 2010).

Diante dos obstáculos encontrados no tratamento de pacientes com queixa de zumbido, percebe-se a necessidade de mudanças para melhorar a reabilitação. Uma das alternativas que vêm surgindo é a adoção do CCP, que a literatura descreve também com outros termos, como, por exemplo: cuidado/abordagem "centrado no cliente" e "centrado no paciente" de maneira intercambiável. Embora a centralização na pessoa não tenha uma definição universal, ela é tipicamente descrita de acordo com cinco dimensões: perspectiva biopsicossocial, cliente como pessoa, poder e responsabilidade compartilhados, aliança terapêutica e clínico como uma pessoa (MEAD; BOWER, 2000).

A centralização na pessoa conduz a uma abordagem biopsicossocial, reconhecendo que a combinação biológica, psicológica e social são necessárias para entender a saúde. No modelo biopsicosocial, o profissional, além da evolução das habilidades técnico-instrumentais, também precisa evoluir as capacidades relacionais que permitem o estabelecimento de um vínculo adequado e uma comunicação efetiva, a fim de assegurar que os problemas e a preocupação dos pacientes são entendidos por aqueles que oferecem o cuidado (DE MARCO, 2006). A Organização Mundial de Saúde (OMS) adota uma perspectiva biopsicossocial; assim, ver o cliente como pessoa se refere à importância de compreender a sua experiência única de doença (WORLD HEALTH ORGANIZATION, 2001).

A comunicação profissional-paciente é essencial no CCP e seu impacto nos resultados de saúde pode ocorrer por diferentes vias. Melhores resultados de intervenção estão associados a respostas afetivas positivas e conversação acolhedora (MILLER, 2002). O diálogo, por si só, pode ser terapêutico, diminuindo diretamente, por exemplo, a ansiedade do paciente. Essa comunicação influencia indiretamente os resultados de saúde, agindo na motivação para o tratamento, na confiança no profissional e no serviço, autoeficácia para o autocuidado e na concordância e na compreensão mútua entre paciente e profissional (STREET et al., 2009).

O CCP destaca a fundamental importância de uma boa relação profissional-paciente para a obtenção de resultados satisfatórios. Além disso, profissional e paciente possuem expertises distintas, que fortalecem o encontro clínico. Dessa forma, o poder e a responsabilidade pelo tratamento devem ser compartilhados (HICKSON et al., 2010; MILLER, 2002). Essa abordagem contrapõe-se ao modelo biomédico, predominante em muitas práticas dos profissionais da audiologia (DUCHAN, 2004). O modelo biomédico é o modelo vigente da atuação na saúde e é regido por variáveis biológicas que analisam o corpo como uma máquina, por meio da relação causa-efeito, minimizando aspectos sociais, psicológicos e as dimensões humanas da doença. É caracterizado por diagnósticos que determinam o modo de tratamento, monopolizado pelo médico, no qual se privilegia a doença e não o doente (GUEDES et al., 2006). Tal modelo, centrado no profissional ou na doença, dá ao profissional maior autoridade e poder de tomada de decisão sobre o tratamento(DUCHAN, 2004). Emprestado da perspectiva humanista de Carl Rogers para a psicologia, o fonoaudiólogo que trabalha no CCP deve ouvir com preocupação, empatia e fornecer consideração positiva incondicional (SWEETOW, 1999).

Os componentes descritos no CCP foram identificados como sendo importantes na tomada de decisão para aquisição do aparelho de amplificação sonora individual (AASI) e no sucesso obtido com esse dispositivo para pessoas com perdas auditivas (POOST-FOROOSH et al., 2011). 
Dentre os impactos causados pela utilização do aparelho na vida desses pacientes, podemos mencionar a amplificação dos sons para sujeitos com perda auditiva, possibilitando que estes voltem a ouvir alguns sons, e proporcionar alívio a indivíduos com sintomas do zumbido. Dessa forma, a utilização do CCP com zumbido poderá trazer ganhos nesse processo, contribuindo para a sensação de confiança, adesão, satisfação e autoestima dos pacientes e, consequentemente, a provável melhora funcional dos sintomas clínicos.

\section{UMA ANÁLISE DIALÓGICA DO DISCURSO DA PROFISSIONAL FONOAUDIÓLOGA SOBRE ZUMBIDO}

A presente seção compreende a análise do discurso do profissional fonoaudiólogo, a fim de averiguarmos a importância de uma boa aplicação enunciativo-discursiva para o bom encaminhamento dos pacientes, em seu início de seção. Para tanto, tomamos como base a Análise Dialógica do Discurso (BRAIT, 2006), doravante ADD, que se instaura em terreno brasileiro como uma teoria que se centra na interação e no dialogismo para averiguação dos discursos e a constituição dos sujeitos.

O presente trabalho traçou como proposta uma abordagem do CCP sob o prisma dialógico, com fundamentação nos pressupostos teórico-metodológicos de Mikhail Bakhtin (1895-1975), Valentin N. Volóchinov (1895-1936) e Pável N. Medviédev (1891-1938), integrantes do Círculo de Bakhtin. Essa proposta viabiliza que profissionais analisem com maior preparo clínico as suas práticas, (re)acentuando metodologias cujo prisma seja a interação. Conforme já explicitado, de oito pacientes que constituíam nossa população, selecionamos como corpora quatro. Para manter a integridade e o compromisso ético, atribuímos nomes fictícios aos pacientes, quais sejam: José, Juliana, Cirineu e Joana.

Nesse direcionamento, construímos os Quadros 1, 2, 3 e 4 que abarcam as perguntas e as respostas que foram edificadas em uma conversa aberta. O CCP preconiza, em seus princípios, a imprescindibilidade da conversa aberta como um gênero comunicativo que se difere dos demais meios de diálogo entre paciente e profissional, porque nesse modelo não existem perguntas ou questionários prontos, como geralmente ocorre em grande parte dos atendimentos nas áreas da saúde. Na conversa aberta, tanto o profissional quanto o paciente podem conduzir o diálogo, de forma que o paciente se sinta em cada encontro mais confortável em falar sobre sua situação de saúde. Tais fatores nos impulsionaram a escolhê-la como método de aplicação dos diálogos.

Quadro 1: Conversa aberta com o paciente José

\begin{tabular}{|l|l|}
\hline \multicolumn{1}{|c|}{ Proposições realizadas pela fonoaudióloga } & \multicolumn{1}{|c|}{ Respostas } \\
\hline $\begin{array}{l}\text { F: O senhor já viu ou ouviu alguma coisa } \\
\text { falando sobre o zumbido, já pesquisou? }\end{array}$ & $\begin{array}{l}\text { J: Não, por curiosidade eu já coloquei na, no } \\
\text { youtube, aí apareceu diversas assim, diversas } \\
\text { programações de lá, de como cuidar do zumbido } \\
\text { como tirar o zumbido cada um que fazia uma coisa } \\
\text { é, mostrar assim uma solução diferente para o } \\
\text { zumbido, como acabar com o zumbido às vezes até } \\
\text { por curiosidade tentei fazer mas não acabou não. }\end{array}$ \\
\hline
\end{tabular}


O CUIDADO CENTRADO NA PESSOA EM PERSPECTIVA DIALÓGICA: UMA ANÁLISE DAS FALAS ENTRE FONOAUDIÓLOGA E PACIENTES COM QUEIXA DE ZUMBIDO

conclusão

\begin{tabular}{|l|l|}
\hline \multicolumn{1}{|c|}{ Proposições realizadas pela fonoaudióloga } & \multicolumn{1}{|c|}{ Respostas } \\
\hline $\begin{array}{l}\text { F: Certo, seu José, e o senhor tem alguma ideia } \\
\text { do que pode estar acontecendo? }\end{array}$ & $\begin{array}{l}\text { J: Não, tenho não, não tenho não, eu só tenho a me } \\
\text { lamentar desse zumbido. }\end{array}$ \\
\hline $\begin{array}{l}\text { F: Pronto, então eu vou lhe explicar um } \\
\text { pouquinho tá certo do que seria esse seu } \\
\text { zumbido, tá? O zumbido, ele é um sintoma, } \\
\text { ele não é uma doença ele é um sintoma, sendo } \\
\text { quando a gente tem um sintoma a gente tem } \\
\text { que procurar saber qual a causa dele. }\end{array}$ & J: Exato, a causa. \\
\hline
\end{tabular}

Fonte: Os autores.

Pelo que podemos depreender da conversa aberta estabelecida com o paciente José, após a fonoaudióloga interrogar sobre ele ter visto, ouvido ou pesquisado alguma coisa falando sobre o zumbido, ele demonstrou possuir curiosidade. José mencionou que já pesquisou, no Youtube, sobre modos de como cuidar do zumbido, em que eram mostradas soluções diferentes para alívio dos sintomas.

Nesse início de conversa, a profissional demonstrou cuidado em relação ao que o paciente já sabia sobre os sintomas de zumbido. Assim, em seguida, perguntou se José tinha alguma ideia do que podia estar acontecendo com relação à permanência do que sentia. Percebemos, discursivamente, que a fonoaudióloga induziu o paciente a refletir sobre os seus próprios sintomas, não apenas de forma empírica, mas de modo mais criterioso, de forma que ele compreendesse mais sobre o que é, de fato, esse sintoma, corroborando as propostas do Ida Institute (2018), no que tange ao CCP.

Conforme Volóchinov (2017, p. 249, grifo do autor), “[...] o estudo produtivo do diálogo pressupõe uma análise mais profunda das formas de transmissão do discurso alheio, pois elas refletem as tendências principais e constantes da percepção ativa do discurso alheio", pois o "discurso alheio", "[...] é o discurso dentro do discurso, o enunciado dentro do enunciado, mas ao mesmo tempo é também o discurso sobre o discurso, o enunciado sobre o enunciado" (VOLÓCHINOV, 2017, p. 252, grifos do autor). Assim sendo, de acordo com os pressupostos dessa abordagem teórica, a palavra ganha existência em função do outro, ela é a "ponte” que interliga os interlocutores pelo fato de não só proceder mas também como se dirigir a alguém (VOLÓCHINOV, 2017). Da forma como a fonoaudióloga se reporta a José, percebem-se relações dialógicas de concordância e de complementaridade entre locutor e interlocutor, organizados socialmente, tendo em vista os papéis sociais assumidos pelos sujeitos interactantes e da própria situação social na sequência de comunicação (MEDVIÉDEV, 2016).

Em seguida, após José dizer que só tinha a se lamentar por causa do Zumbido, a cientista se propôs a explicar um pouco o que seria esse zumbido, e mencionou que se trata de um sintoma. Nesse sentido, o zumbido não é uma doença, apenas algo sintomático, e que é preciso sim procurar saber qual a causa dele. Na escuta aberta, é possível perceber, por parte da fonoaudióloga, não apenas empatia, mas também o compartilhamento de informações importantes sobre o sintoma de zumbido, e isso no intuito de contribuir positivamente no tratamento. Percebe-se que as perguntas ajudam a determinar se o paciente vivencia o zumbido como um som ou como uma dor física e/ou emocional (IDA INSTITUTE, 2018). 
De igual modo, observemos como se procedeu a conversa aberta com a paciente Juliana:

Quadro 2: Conversa aberta com a paciente Juliana

\begin{tabular}{|l|l|}
\hline Proposições realizadas pela fonoaudióloga & \multicolumn{1}{|c|}{ Respostas } \\
\hline $\begin{array}{l}\text { F: Então, eu queria saber da senhora uma uma } \\
\text { coisa, quando a senhora pensa no seu zumbido, } \\
\text { o que é que você acha? }\end{array}$ & $\begin{array}{l}\text { J: Eu me sinto incomodada, é incomodo demais, } \\
\text { demais sabe? Dá assim aquele desengano, aquela } \\
\text { coisa ruim, porque você pensa como era e como tá } \\
\text { sendo agora, sabe? }\end{array}$ \\
\hline $\begin{array}{l}\text { F: Então, a senhora lembra como era antes } \\
\text { dele? Não tinha essa preocupação? }\end{array}$ & $\begin{array}{l}\text { J: Ah, eu lembro... eu ia dormir era tranquilo, } \\
\text { aquela coisa bem tranquila, agora é "Shhhiii”, } \\
\text { entendeu? E agora não me larga! Aí junta com o } \\
\text { estresse, porque tem dias que tô só Deus, hoje é } \\
\text { um deles. }\end{array}$ \\
\hline $\begin{array}{l}\text { F: É né.. mas pronto a senhora pode ficar mais } \\
\text { calma agora tá certo, que a gente tá aqui pra } \\
\text { tentar lhe ajudar tá? Nem se preocupe, eu } \\
\text { tô aqui pra isso mesmo, pra conversar pra } \\
\text { entender como a senhora tá se sentindo, não só } \\
\text { a respeito do seu zumbido, mas também tudo } \\
\text { que tá por volta dele... }\end{array}$ & Já. \\
\hline
\end{tabular}

Fonte: Os autores.

Ao averiguarmos a conversa aberta estabelecida com a paciente Juliana, inicialmente a fonoaudióloga interrogou sobre o que a paciente achava quando pensava no seu zumbido. Essa interpelação inicial ajudou o profissional a precisar se seu paciente estava vivenciando o zumbido como um som ou dor física e/ou emocional. Juliana respondeu que se sente bastante incomodada, e que tais desconfortos causam sensação de desengano, sensações ruins, quando compara com os períodos em que não possuía zumbido. A fonoaudióloga, então, fez a pergunta: “Então a senhora lembra como era antes dele?”, e Juliana afirmou que lembra sim, e mencionou que, quando ia dormir, era tranquilo, um ambiente de quietude e tranquilidade, diferente do “Shhhiii”, que é constante agora, devido ao zumbido. Para Volóchinov (2017):

A importância da orientação da palavra para o interlocutor é extremamente grande. Em sua essência, a palavra é um ato bilateral. Ela é determinada tanto por aquele de quem ela procede quanto por aquele para quem se dirige. Enquanto palavra, ela é justamente o produto das inter-relações do falante com o ouvinte. Toda palavra serve de expressão ao "um” em relação ao "outro”. Na palavra, eu dou forma a mim mesmo do ponto de vista do outro e, por fim, da perspectiva da minha coletividade. A palavra é uma ponte que liga o eu ao outro. Ela apoia uma das extremidades em mim e a outra no interlocutor. A palavra é o território comum entre o falante e o interlocutor (VOLÓCHINOV, 2017, p. 205).

Então, chegou o momento que a fonoaudióloga, utilizando-se da abordagem do CCP, afirmou que a paciente poderia ficar mais calma, e que sua função enquanto profissional é tentar ajudar. Pediu, então, para que Juliana não se preocupasse, porque é seu papel conduzir a conversa no sentido de compreender como ela se sentia em relação ao zumbido, e, também, 
as circunstâncias, os fatores externos que podiam agravar ou influenciar. Constata-se que as perguntas abertas conduzem a paciente a articular os seus pensamentos e as suas perguntas em relação ao zumbido. Assim, é possível trabalhar para esclarecer conceitos equivocados que eles possam ter (IDA INSTITUTE, 2018).

Percebe-se, em âmbito dialógico, que a fonoaudióloga está tentando “[...] detectar os compromissos que se criam por meio da fala e as condições que devem ser preenchidas por um falante para falar de certa forma em determinada situação concreta de interação” (GERALDI, 2006, p. 42).

A seguir, é possível, também, perceber como houve a conversa aberta em relação ao paciente Cirineu.

Quadro 3: Conversa aberta com o paciente Cirineu

\begin{tabular}{|c|c|}
\hline Proposições realizadas pela fonoaudióloga & Respostas \\
\hline $\begin{array}{l}\text { F: Eu queria saber um pouquinho como é que o } \\
\text { senhor ser sente a respeito disso, o seu zumbido, } \\
\text { como o senhor se sente... }\end{array}$ & $\begin{array}{l}\text { C: Eu me sinto muito agoniado, aperreado demais, } \\
\text { vontade de fazer as coisas não tenho vontade de } \\
\text { fazer nada, só você vendo. Dormia bem de dia, } \\
\text { nunca mais consegui dormir de dia, eu era muito, } \\
\text { eu era uma pessoa que tinha uma atividade fora do } \\
\text { comum, hoje não tenho mais. }\end{array}$ \\
\hline F: O senhor tá vendo essa listrinha laranja? & C: Tô \\
\hline $\begin{array}{l}\text { F: Ela é como se fosse seu zumbido tá certo? } \\
\text { Tá vendo a listrinha azul? Ela é como se fosse } \\
\text { o incomodo que o senhor sente do zumbido, tá } \\
\text { bom? Tá vendo que aqui embaixo tem algumas } \\
\text { carinhas? É como se essas carinhas fossem o } \\
\text { passar do tempo, tá bom? Então, eu quero que } \\
\text { o senhor saiba que o seu zumbido pode sempre } \\
\text { tá presente com o senhor, certo? Mas, com o } \\
\text { passar do tempo, pode ser que ele passe a ser } \\
\text { menos incomodo, que o senhor passe a perceber } \\
\text { menos a ponto de não incomodar mais como tá } \\
\text { lhe incomodando hoje. }\end{array}$ & $\begin{array}{l}\text { C: Tô vendo, lá em cima. } \\
\text { C: Pra suas palavras digo amém. }\end{array}$ \\
\hline
\end{tabular}

Fonte: Os autores.

Em seu discurso, a fonoaudióloga iniciou mencionando para Cirineu que queria saber um pouquinho como é que ele se sentia a respeito do zumbido. Essa pergunta introjetou uma perspectiva de autorreflexão no paciente, na medida em que ajuda a determinar as problemáticas sensitivas do zumbido a exemplo de se tratar de uma dor física e/ou emocional (IDA INSTITUTE, 2018). O paciente Cirineu afirmou que estava "muito agoniado, aperreado demais”, "vontade de fazer as coisas não tenho vontade de fazer nada, só você vendo”. Assim, ele narrou que, antes de sentir o zumbido, dormia bem de dia; já nos dias atuais, nunca mais conseguiu dormir de dia, pois era uma pessoa que tinha uma atividade fora do comum, e hoje não tem mais. Essas perguntas abertas geram respostas reflexivas, ao contrário do mecanismo utilizado no caso de perguntas objetivas. 
Sob as lentes da abordagem dialógica, o discurso reflexivo é de caráter interativo, e atua como realidade fundamental (BAKHTIN, 2006a), pois interessam as vozes do discurso de forma que falante e ouvinte formam a sua consciência linguística (VOLÓCHINOV, 2017). Desse modo, o procedimento utilizado pela fonoaudióloga, tendo em vista o CCP, permite que o profissional abra espaço para que sejam compartilhados pensamentos e sentimentos sobre como o zumbido afeta a vida de cada um.

Então, após a fonoaudióloga em atendimento fazer uma analogia entre o zumbido e um instrumento com cores, afirmou que, da mesma forma em que existem intensidades de cor forte e mais fraca, o zumbido, apesar de sempre estar presente, mas com o passar do tempo pode ser que ele passe a ser menos incômodo, e que Cirineu passará a perceber menos agonia a ponto de não incomodar mais, ao contrário do desconforto que sente atualmente. Esse tipo de procedimento dialógico e discursivo (BAKHTIN, 2006a) nas conversas com o paciente contribui positivamente para que este trabalhe as emoções difíceis em sua vida (IDA INSTITUTE, 2018), e o ajuda a se sentir menos sozinho. O diálogo ajuda a focar no tratamento do paciente e nas necessidades individuais de cada um.

Por último, dentre os sujeitos selecionados para parte analítica, dispõe-se a escuta aberta com Joana.

Quadro 4: Conversa aberta com a paciente Joana

\begin{tabular}{|l|l|}
\hline Proposições realizadas pela fonoaudióloga & \multicolumn{1}{|c|}{ Respostas } \\
\hline $\begin{array}{l}\text { F: Eu queria que a senhora agora pensasse se } \\
\text { pudesse descrever seu zumbido em duas ou } \\
\text { uma palavra o que a senhora me dizia, o que } \\
\text { a senhora sente em uma palavra ou duas em } \\
\text { relação ao zumbido. }\end{array}$ & $\begin{array}{l}\text { J: olhe eu vou dizer uma coisa a você o que eu } \\
\text { sinto com relação ao zumbido, eu sinto muito } \\
\text { me aperreio e outra coisa porque ele me estressa. }\end{array}$ \\
\hline $\begin{array}{l}\text { F: Humrum, tô entendendo. Olhe, mas olhe, a } \\
\text { gente tá aqui pra lhe ajudar viu? (segurando na } \\
\text { mão da paciente) }\end{array}$ & $\begin{array}{l}\text { J: (balançando a cabeça concordando), é muito } \\
\text { difícil minha filha (chorando). }\end{array}$ \\
\hline $\begin{array}{l}\text { F: A senhora tá aqui agora e eu queria que a } \\
\text { senhora soubesse o seguinte, que a senhora não } \\
\text { tá sozinha certo? }\end{array}$ & $\begin{array}{l}\text { J: Humrum (concordando, com a cabeça). Melhor, } \\
\text { melhor pro meu bem-estar. }\end{array}$ \\
\hline
\end{tabular}

Fonte: Os autores.

A princípio, na conversa com Joana, a profissional afirmou que gostaria que ela descrevesse o zumbido em duas ou uma palavra, ou seja, o que ela sentia em uma palavra ou duas em relação ao zumbido. Joana não falou uma ou duas palavras, mas mencionou que sentia muito desgosto, e que, às vezes, tinha muita vontade de chorar, aborrecia-se, de forma que quaisquer fatores externos acabavam causando estresse.

Após a efetivação dessa pergunta norteadora inicial, a fonoaudióloga mencionou, então, que estava ali na representação de pessoas que se dispunham a ajudar, a contribuir para melhoria na qualidade de vida, tendo em vista possíveis ações em relação ao zumbido: "Humrum, tô entendendo. Olhe, mas olhe, a gente tá aqui pra lhe ajudar viu? (segurando na mão da paciente)”. E “A senhora tá aqui agora e eu queria que a senhora soubesse o seguinte, que a senhora não tá sozinha certo?”. 
Nesse momento, é nítido o princípio da empatia por parte da profissional, uma vez que ela está dando espaço ao seu paciente para que ele expresse suas emoções, mostrando que compreende os seus sentimentos. É possível mostrar empatia com comentários que dão certeza para o paciente de que se está escutando ativamente, como: "Eu entendo que você quer que seu zumbido vá embora. - Eu também queria que isso acontecesse” (IDA INSTITUTE, 2018). É possível verificar que a aplicabilidade do princípio de empatia corrobora o ato dialógico de que "Não pode haver enunciado isolado. Ele sempre pressupõe enunciados que o antecedem e o sucedem. Nenhum enunciado pode ser o primeiro ou o último. Ele é apenas o elo na cadeia e fora dessa cadeia não pode ser estudado" (BAKHTIN, 2006b, p. 351, grifos nossos).

Diante de toda a interação discursiva (VOLÓCHINOV, 2017) presente nas conversas, foi possível perceber que a profissional fonoaudióloga, a partir do momento que se utilizou de mecanismos de linguagem sob abordagem do CCP, trouxe elementos eficazes e ricos, que contribuem para melhoria na qualidade de vida dos pacientes.

\section{CONSIDERAÇÕES FINAIS}

Nossas reflexões circunscreveram a importância do aparato teórico-metodológico do dialogismo para aprofundamento de análises de discursos, em que é possível averiguar os posicionamentos assumidos por profissionais em seus locais de trabalho. Por meio da perspectiva dialógica, foi possível realizar uma análise do discurso do profissional fonoaudiólogo durante o atendimento de pacientes com zumbido utilizando o Cuidado Centrado na Pessoa.

A constatação da eficácia da conversa aberta por meio da Interação discursiva (VOLÓCHINOV, 2017) revela uma das contribuições que vêm sendo evidenciadas pela teoria bakhtiniana da linguagem, que não compreende os sujeitos como objetos fechados nem mecânicos, mas como seres constitutivamente dialógicos. Os resultados destacaram a importância do enfoque do CCP na prática em âmbito dialógico, visto que ele melhora a adesão e a eficácia do tratamento de pacientes com zumbido.

Em meio a esse povoamento de palavras, esperamos que esta pesquisa inspire outros trabalhos que problematizem estudos sobre as contribuições de dois grandes núcleos embasadores: a) o Cuidado Centrado na Pessoa, cuja metodologia fortalece o modo como profissionais irão se posicionar frente a seus pacientes; e b) Os estudos discursivos para práticas clínicas, como no caso do atendimento da profissional fonoaudióloga.

\section{REFERÊNCIAS}

AZEVEDO, A. A. et al. Análise crítica dos métodos de mensuração do zumbido. Revista Brasileira de Otorrinolaringologia, São Paulo, v. 73, n. 3, p. 418-423, 2007. DOI: https:// doi.org/10.1590/S0034-72992007000300019

BAGULEY, D.; MCFERRAN, D.; HALL, D. Tinnitus. The Lancet, [s. l.], v. 382, n. 9904, p. 1600-1607, 2013. DOI: https://doi.org/10.1016/S0140-6736(13)60142-7

BAKHTIN, M. Gêneros do Discurso. In: BAKHTIN, M. Estética da criação verbal. Tradução Paulo Bezerra. 4. ed. São Paulo: Martins Fontes, 2006a. p. 261-306. 
BAKHTIN, M. Reformulação do livro sobre Dostoiévski. In: BAKHTIN, M. Estética da criação verbal. Tradução Paulo Bezerra. 4. ed. São Paulo: Martins Fontes, 2006b. p. 337-358.

BAKHTIN, M. Para uma filosofia do Ato Responsável.Tradução Valdemir Miotello e Carlos Alberto Faraco. São Carlos: Pedro \& João Editores, 2010.

BARLOW, J. et al. Self-management approaches for people with chronic conditions: a review. Patient Education and Counseling, [s. l.], n. 48, p. 177-187, 2002. DOI: https://doi. org/10.1016/s0738-3991(02)00032-0

BRAIT, B. Análise e Teoria do Discurso. In: BRAIT, B. (org.). Bakhtin: outros conceitoschave. São Paulo: Contexto, 2006. p. 9-31.

DE MARCO, M. A. Do Modelo Médico ao Modelo Biopsicossocial: um projeto de educação permanente. Revista Brasileira de Educação Médica, Rio de Janeiro, v. 30, n. 1, p. 60-72, 2006. DOI: https://doi.org/10.1590/S0100-55022006000100010

DUCHAN, J. Maybe audiologists are too attached to the medical model. Semin Hearing, [s. l.], v. 25, n. 4, p. 347-54, 2004.

DWAMENA, F. et al. Interventions for providers to promote a patient-centred approach in clinical consultations. Cochrane Database of Systematic Reviews, [s. l.], n. l, v. 1, p. 1-13, 2012. DOI: https://doi.org/10.1002/14651858.CD003267.pub2

ESTEVES, C. C. et al. Audição, zumbido e qualidade de vida: um estudo piloto. Revista CEFAC, Campinas, v. 14, n. 5, p. 836-843, 2012. DOI: https://doi.org/10.1590/S151618462011005000107

FIGUEIREDO, R. R.; AZEVEDO, A. A. de; OLIVEIRA, P. de M. Análise da correlação entre a escala visual-análoga e o Tinnitus Handicap Inventory na avaliação de pacientes com zumbido. Revista Brasileira de Otorrinolaringologia, São Paulo, v. 75, n. 1, p. 76-79, 2009. DOI: https://doi.org/10.1590/S0034-72992009000100012

GERALDI, J. W. Concepções de linguagem e ensino de Português. In: GERALDI, J. W. et al. (org.). O texto na sala de aula. 4. ed. São Paulo: Ática, 2006. p. 39-53.

GOULART, B.; CHIARI, B. Humanização das práticas do profissional de saúde: contribuições para reflexão. Ciência \& Saúde Coletiva, Rio de Janeiro, v. 15, n. 1, p. 255-68, 2010. DOI: https://doi.org/10.1590/S1413-81232010000100031

GRANJEIRO, R. C. et al. Transient and distortion product evoked oto-acoustic emissions in normal hearing patients with and without tinnitus. Otolaryngology-Head and Neck Surgery: Official Journal of American Academy of Otolaryngology-Head and Neck Surgery, [s. l.], v. 138, n. 4, p. 502-506, 2008.

GRENNESS, C. et al. Reabilitação audiológica centrada no paciente: perspectivas de idosos que possuem próteses auditivas. International Journal of Audiology, [s. l.], v. 53, p. 68-75, 2014.

GUEDES, C. et al. A subjetividade como anomalia: contribuições epistemológicas para a crítica do modelo biomédico. Ciência \& Saúde Coletiva, Rio de Janeiro, v. 11, p. 1-14, 2006. 
O CUIDADO CENTRADO NA PESSOA EM PERSPECTIVA DIALÓGICA: UMA ANÁLISE DAS FALAS ENTRE FONOAUDIÓLOGA E PACIENTES COM QUEIXA DE ZUMBIDO

GUIMARÃES, A. C. et al. Study of the relationship between the degree of tinnitus annoyance and the presence of hyperacusis. Brazilian Journal of Otorhinolaryngology, São Paulo, v. 80, n. 1, p. 24-28, 2014. DOI: https://doi.org/10.5935/1808-8694.20140007 HENRY, J. A et al. Revisão geral do zumbido: prevalência, mecanismos, efeitos e manejo. Journal of speech, language, and hearing research, [s. l.], n. 48, p. 1204-1235, 2005.

HICKSON, L. et al. Promoting the participation of adults with acquired hearing impairment in their rehabilitation. Journal of the Academy of Rehabilitative Audiology, [s. l.], n. 43, p. 11-26, 2010.

IDA INSTITUTE. Tinnitus Management. 2018. Disponível em: https://idainstitute.com/ tools/tinnitus/. Acesso em: 10 fev. 2020.

LAPLANTE-LÉVESQUE, A. et al. Um estudo qualitativo da tomada de decisão compartilhada em audiologia de reabilitação. Journal of the Academy of Rehabilitative Audiology, [s. l.], n. 43, p. 27-43, 2011.

LAWN S; SCHOO, A. Supporting self-management of chronic health conditions: Common approaches. Patient Education and Counseling, [s. l.], n. 80, p. 205-211, 2010.

MEAD, N.; BOWER, P. Patient-centredness: a conceptual framework and review of the empirical literature. Social Science and Medicine, [s. l.], n. 51, p. 1087-1110, 2000.

MEDVIÉDEV, P. A linguagem poética como objeto da poética. In: O método formal nos estudos literários: Introdução crítica a uma poética sociológica. Tradução de Sheila Camargo Grillo e Ekaterina Vólkova Américo. 2. ed. São Paulo: Contexto, 2016. p. 131-163.

MICHIE, S. et al. Centrado no paciente na doença: o que é e isso importa? Patient Education and Counseling, [s. l.], n. 51, p. 197-206, 2003.

MILLER, E. Telemedicine and doctor-patient communication: a theoretical framework for evaluation. Journal of Telemed Telecare, [s. l.], v. 8, n. 6, p. 311-318, 2002.

NONDAHL, D. M. et al. Tinnitus and its risk factors in the Beaver Dam offspring study. International Journal of Audiology, [s. l.], v. 50, n. 5, p. 313-320, 2011. DOI: https://doi.or g/10.3109/14992027.2010.551220

OITICICA, J.; BITTAR, R. S. M. Tinnitus prevalence in the city of São Paulo. Brazilian Journal of Otorhinolaryngology, São Paulo, n. 81, p. 167-76, 2015. DOI: https://doi. org/10.1016/j.bjorl.2014.12.004

ONISHI, E. T. et al. Tinnitus and sound intolerance: evidence and experience of a Brazilian group. Brazilian Journal of Otorhinolaryngology, São Paulo, n. 84, p. 135-149, 2018. DOI: https://doi.org/10.1016/j.bjorl.2017.12.002

POOST-FOROOSH, L. et al. Factors in client-clinician interaction that influence hearing aid adoption. Trends Amplif., [s. l.], v. 15, n. 3, p. 127-39, 2011. DOI: https://dx.doi. org/10.1177\%2F1084713811430217

ROSA, M. R. D. et al. Zumbido e ansiedade: uma revisão da literatura. Revista CEFAC, Campinas, v. 14, p. 742-754, 2012. DOI: https://doi.org/10.1590/S1516-18462012005000009 
SANCHEZ, T. G. et al. Zumbido: características e epidemiologia. Experiência do Hospital das clínicas da Faculdade de Medicina da Universidade de São Paulo. Revista Brasileira de Otorrinolaringologia, São Paulo, v. 63, n. 3, p. 229-235, 1997.

SANTANA, W. K. F. Explorando as multifaces da palavra: sobre a emergência de ultrapassar o teoreticismo e o imanentismo na/da linguagem. Re-unir Revista, Porto Velho, v. 6, n. 1, p. 65-80, 2019a.

SANTANA, W. K. F. A ciência das ideologias e a filosofia da linguagem: nas tessituras de Volóchinov e o Círculo de Bakhtin. Revista Diálogos, Dossiê Relendo Bakhtin, Maringá, v. 7, n. 3, p. 205-220, out./dez. 2019b.

STARFIELD, B. Is patient-centered care the same as person-focused care? Portland: The Permanente Journal, [s. l.], v. 15, n. 2, p. 63-69, 2011.

STREET, R. L. et al. How does communication heal? Pathways linking clinician-patient communication to health outcomes. Patient Education and Counseling, [s. l.], v. 74, n. 3, p. 295-301, 2009.

SWEETOW, R. Counseling for hearing aid fittings. San Diego: Singular, 1999.

TODOROV, T. Prefácio. In: BAKHTIN, M. Estética da criação verbal. Tradução Paulo Bezerra. 5. ed. São Paulo: WMF Martins Fontes, 2006.

VOLOCHÍNOV, V. Marxismo e filosofia da linguagem - Problemas fundamentais do método sociológico na ciência da linguagem. Tradução de Sheila Grillo e Ekaterina Vólkova Américo; Ensaio introdutório de Sheila Grillo. São Paulo: Editora 34, 2017.

WORLD HEALTH ORGANIZATION. International classification of functioning, disability, and health. Geneva: WHO, 2001. 